\title{
Automatic polarographic elucidation of electrode mechanisms by means of a knowledge-based system
}

\section{Part 3. Mechanisms ECE, EE and mechanisms involving adsorption}

\author{
M.J. Pałys ${ }^{1}$, M. Bos and W.E. van der Linden \\ Laboratory for Chemical Analysis, Department of Chemical Technology, Twente University of Technology, P.O. Box 217, \\ 7500 AE Enschede (Netherlands)
}

(Received 8th February 1993; revised manuscript received 19th March 1993)

\begin{abstract}
The previously described expert system has been extended: rules allowing the elucidation of a larger number of mechanisms have been added and automatic control of additional experimental parameters such as concentration and composition of the solution in the cell and the electrode size has been made possible. The new rules cover a number of mechanisms consisting of two electron transfer steps (ECE, EE, "square" and "triangle" schemes) and simple mechanisms in which either the reactant or the product undergoes a fast, reversible adsorption. Previously used criteria for the detection of a net reaction in the system and for the determination of the type of the electron transfer were made more robust by combining results obtained with cyclic voltammetry and convolution voltammetry. With the present set of rules, the expert system is capable to evaluate 39 mechanisms and their variants. To validate this set, the system was run with a number of compounds for which reaction mechanisms have already been studied. In all cases, the mechanism found as the most probable was the correct one. The time of the elucidation depended on the number of experiments that had to be done and varied from 4 up to $6 \mathrm{~h}$. During this time, the system worked practically without human supervision.
\end{abstract}

Keywords: Polarography; Voltammetry; Electrode mechanisms; Knowledge-based systems

In two previously published papers $[1,2]$ a knowledge-based (expert) system, capable to elucidate simple electrode reaction mechanisms in a fully automatic manner, has been described. The set of rules for the elucidation in that system covered a number of mechanisms where a single electron transfer step (ETS), possibly coupled to a homogeneous chemical reaction, occurred. Currently, this set has been extended and improved: more complicated mechanisms, where two electron transfer steps take place (EE and ECE mechanisms) and a number of instances of "tri-

1 On leave from the Department of Chemistry, University of Warsaw and author for correspondence. angle" and "square schemes", mechanisms often encountered among electrochemical processes of complexes (see below), have been included

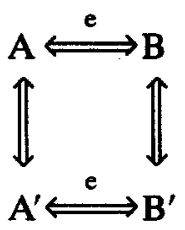

or<smiles>[Te][Te][Te][Te]</smiles> 
Additionally, rules have been provided for the elucidation of simple mechanisms involving either strong or weak adsorption of the substrate or the product of the charge transfer.

Generally, the method of reasoning, the representation of knowledge and the principal structures of the expert system remained identical to those described previously [2]. The main change was the addition of new experimental parameters that can be controlled by the expert system and the improvement of the user interface. At present, the expert system can control two (or more) burettes and a pump, which allows to vary the concentration of the electroactive compound, as well as to replace the solution to start a new series of experiments without the need of human intervention. The size of the mercury drop used as the electrode can be varied, too, giving on one hand a tool to study spherical diffusion effects and on the other hand, to eliminate them. All these changes significantly improved the degree of automation of the whole system.

Changes in the user interface resulted in a capability to generate extensive reports on the elucidation as well as to produce semi-graphic representation of decision trees, showing how the system has reached the final conclusion about the reaction mechanism.

EXTENSIONS AND IMPROVEMENTS OF THE EXISTING RULE SET

Substantial improvements of old rules defining the determination of factors controlling the transport to the electrode and the detection of a net chemical reaction in the system have been carried out. The new versions of rules are either based on more complete experimental evidence or they are better theoretically supported.

\section{Net reaction}

Irreversible steps (of electrochemical or chemical character) in cyclic voltammetry cause consumption of the substrate(s) during the measurement leading to the presence of a net reaction in the system. A criterion for the detection can be based on the restoration of the initial state at the electrode surface after a cyclic change of the potential: if a net reaction does not occur, the surface concentration of all species after the experiment should be exactly the same as before. If there is a net reaction, concentrations will differ.

In the previous version of the expert system, the rule for the detection of a net reaction was based on an arbitrary criterion: if the charge passed during the voltammetric backward scan was less than $50 \%$ of the charge passed during the forward scan, the hypothesis that there is a net effect was accepted. Currently, the surface concentrations are explored as primary quantities and a combination of criteria based on convolution voltammetry and cyclic voltammetry is used.

Because the charge is only indirectly related to the surface concentrations, the direct application of the latter quantities is the better approach. The value proportional to the surface concentration of the product of an electrode reaction during the experiment can be obtained by convolution [3-5] of the voltammetric current with a $(\pi t)^{-1 / 2}$ function (semi-integration) $[6,7]$

$i(t) * g(t)=n F A D^{1 / 2} c^{\mathrm{s}}(t)$

where $n, F, A$ and $D$ having their usual electrochemical meaning, $i(t)$ being current, $c^{\mathrm{s}}(t)$ the surface concentration and $g(t)$ the convolution function, equal to $(\pi t)^{-1 / 2}$. Equation 1 is valid under the assumption, that the transport to and from the electrode can be described by semi-infinite linear diffusion. In practice, however, the assumption about the linearity of the diffusion is rarely valid and therefore it is better to use so-called spherical convolution [7], delivering the surface concentration of the product under mixed (linear and spherical) diffusion conditions that are much more frequently encountered. A method presented in a paper by Engblom and Oldham [8] is even better, because it takes into account that datapoints could be acquired using staircase voltammetry rather than the linear sweep method. The disadvantage is that it requires the value of the diffusion coefficient, which is often unknown or not exactly known.

The semi-integral criterion for the presence of a net reaction can then be formulated as follows: if the initial concentration of the compound is 
restored, the convolute value should return exactly to its initial value (usually zero) after the cycle is completed, which means that the product of the reaction has been converted back to the substrate [7,9]. If it does not return to its original value, consumption of the initially present substance is suggested.

The convolution criterion alone is insufficient, because the substrate or the product of the reaction can be accumulated on (or in) the electrode by adsorption, deposition or amalgamation. In this case, the initial value of the surface concentration is not restored after the completion of the voltammetric cycle and convoluted voltammograms will not deliver proper results. However, if the accumulation effect becomes dominant, an alternative approach is possible: because there is no loss of the compound by its diffusing away, the total charge passed during the voltammetric cycle should approach zero.

Because the possible reaction consuming the reagent can be either slow or fast compared to the time scale of the experiment, both criteria should be evaluated for a number of different scan rates. Deviations from zero can then be checked using statistical tests; consequently, the probability that a net reaction occurs is a conjunction of probabilities that both normalized charge and normalized convolute (semi-integral) differ from zero.

\section{Characteristics of separate signals}

Suggestion of the mechanism of observed signals. The philosophy of rules characterizing the separate signals has not been changed, but the rules have been given broader theoretical founda- tions and multiple techniques have been employed to obtain experimental information.

Suggestions for mechanisms, previously exclusively based on the Nicholson and Shain criteria involving variation of voltammetric peak potential with scan rate [10], have been extended to semidifferential voltammetry for cases of uncomplicated, fast and slow electron transfers. According to Goto and Ishii [11], the semiderivative peak obtained in the case of a fast, uncomplicated electron transfer step can be described using the equation

$$
\begin{aligned}
\mathrm{d}^{1 / 2} i / \mathrm{d} t^{1 / 2}= & \left(n^{2} F^{2} A v C D^{1 / 2} / 4 R T\right) \\
& \times \cosh ^{-2}\left[(n F / 2 R T)\left(E-E_{1 / 2}\right)\right]
\end{aligned}
$$

where, $c, R, T$ and $E$ have their usual meaning, $v$ is a scan rate and $E_{1 / 2}$ is a polarographic halfwave potential of the reacting redox couple. It is found, that the peak appears at a potential value equal to $E_{1 / 2}$ irrespective of the scan rate used; the peak height is represented by the expression $n^{2} F^{2} A v C D^{1 / 2} / 4 R T$ and it increases linearly with the scan rate.

In case of a slow, uncomplicated electron transfer, the semiderivative peak can be described with the following equation [12]:

$$
\begin{aligned}
\mathrm{d}^{1 / 2} i / \mathrm{d} t^{1 / 2}= & \left(n^{2} \alpha F^{2} A v C D^{1 / 2} / R T\right) \\
& \times \sum_{j=1}^{\infty}(-1)^{j} \exp (j z)(j !)^{-1 / 2}
\end{aligned}
$$

where $z=(n \alpha F / R T)\left(E^{0^{\prime}}-E\right)+\frac{1}{2} \ln \left(R T k_{\mathrm{s}} /\right.$ $n \alpha F v D), k_{\mathrm{s}}$ being the standard heterogeneous rate constant. The maximum value of the sum,

\begin{tabular}{|c|c|c|c|c|}
\hline \multirow{2}{*}{$\begin{array}{l}\text { Suggestion of the mechanism } \\
\text { of electron transfer step (ETS) }\end{array}$} & \multicolumn{2}{|c|}{ Trend of semiderivative } & \multicolumn{2}{|c|}{ Value of semiderivative } \\
\hline & $\mathrm{d} E_{\mathrm{p}} / \mathrm{d} v$ vs. $v$ & $\mathrm{~d} E_{\mathrm{p}} / \mathrm{d} \ln v$ vs. $v$ & $\mathrm{~d} E_{\mathrm{p}} / \mathrm{d} v$ vs. $v$ & $\mathrm{~d} E_{\mathrm{p}} / \mathrm{d} \ln v$ vs. $v$ \\
\hline $\mathbf{E}$ & Constant & & 0 & \\
\hline $\begin{array}{l}\text { Es (cathodic branch) } \\
\text { Es (anodic branch) }\end{array}$ & & $\begin{array}{l}\text { Constant } \\
\text { Constant }\end{array}$ & & $\begin{array}{l}<-R T / 2 n F \\
>R T / 2 n F\end{array}$ \\
\hline
\end{tabular}

TABLE 1

Diagnostic criteria for suggestion of mechanism of the ETS, based on semiderivative staircase voltammetry (Acronyms as in the Table 4 in Ref. 2) 
0.2970 , occurs at $z=-0.055$ and the potential of the semiderivative peak can be expressed as

$$
\begin{aligned}
E_{\mathrm{p}}= & {\left[E^{0^{\prime}}+0.055 R T / \alpha n F\right.} \\
& \left.+(R T / 2 \alpha n F) \ln \left(R T k_{\mathrm{s}} / \alpha n F D\right)\right] \\
& -(R T / 2 \alpha n F) \ln v
\end{aligned}
$$

showing a linear dependence on the logarithm of the scan rate. The peak height equals

\section{$0.2970 n^{2} \alpha F^{2} A v C D^{1 / 2} / R T$}

On the basis of these equations, the diagnostic criteria collected in Table 1 can be established.

Control of the transport to the electrode. As far as factors controlling the transport of electroactive substance to the electrode are concerned, a larger number of different situations is considered than before and more techniques are employed. The main line of reasoning, i.e., description of different types of transport as deviations from the semi-infinite linear diffusion, is preserved. The transport can be larger than in semiinfinite linear diffusion, for example if spherical diffusion or kinetic effects (chemical or catalytic reaction) take place; in this latter case it can even lead to a steady state. Lower intensity of the transport can be observed in cases of limited diffusion and reactions from the adsorbed state. In the latter case, the whole amount of substance adsorbed reacts within a very short time and the current drops sharply to zero after exhaustion of the component.

In the current set of rules, criteria based on cyclic chronocoulometry, staircase voltammetry and convolution voltammetry are employed. In chronocoulometry, according to Anson [13], the quantity of charge in cyclic chronocoulometry can be described using the equation

$Q=2 n F A D^{1 / 2} C \pi^{-1 / 2} t^{1 / 2}$

and

$Q(t>\tau)=2 n F A D^{1 / 2} C \pi^{-1 / 2}\left[t^{1 / 2}-(t-\tau)^{1 / 2}\right]$

if, after the time $\tau$, the potential is changed to a value at which the concentration of the product of the reaction is zero (semi-infinite linear diffu- sion assumed). One can find, that the charge passed in each half-cycle should vary linearly with the square root of the time elapsed from the beginning of the half-cycle. If additional contributions enhance the transport, the charge is greater than predicted from the purely linear model. The inverse effect appears when the transport is slower than for linear diffusion (limited diffusion, strong adsorption of product or substrate on the electrode): the observed charge increases slower and for adsorbed species it can even reach a constant value almost instantaneously.

A unique effect can be observed in the case of weak adsorption of the reactant: effects of the reaction of diffusing species (visible in long times) and adsorbed ones (observable in short times) are combined, the plot $Q$ vs. $t^{-1 / 2}$ is linear, but shifted along the charge axis with an amount corresponding to the charge consumed in the reaction of the substance present at the electrode surface.

In staircase voltammetry (SCV), information about the transport of the reactant to the electrode surface is primarily included in the height of the voltammetric peak and in its shape, particularly in the form of the descending branch of the peak. As before, different types of transport can be treated as distortions of the semi-infinite linear diffusion caused by, e.g., chemical processes, depletion of the bulk of the solution, etc. All these effects, except adsorption, have one common feature: they become more important with time and their influence is better visible at slow scan rates.

To derive appropriate criteria, a classic analysis of Nicholson and Shain [10] can be employed: the measured current follows the equation

$i=c_{0} v^{1 / 2} \chi\left(c_{1} t\right)$

where $c_{0}$ represents a general proportionality constant, $c_{1}$ is the constant relating the time scale of the experiment to the time scale of the phenomena involved, $v$ is the scan rate and $\chi\left(c_{1} t\right)$ is a function defining the peak shape. The constant $c_{1}$ is different for various mechanisms, but independent of the scan rate if the flux of the substance at the electrode surface is governed by semi-infinite linear diffusion. In such cases, the 
variation of the height of the voltammetric peak should be linear with the square root of the scan rate.

For mixed spherical and linear diffusion the situation is different: the increased flux of the electroactive substance leads to an increase of the recorded currents. The quantitative description of the effect is difficult, but it can be intuitively expected that the peak height will no longer be linearly dependent on $v^{1 / 2}$, particularly in the slow scan rate region. The current in the descending branch of the peak will also deviate from a $t^{-1 / 2}$ decay with an increasing distance from the top of the peak and with a decrease of the scan rate. A qualitatively very similar effect can be observed when an extra amount of substance is delivered in a chemical way. In the extreme case, the production rate of the reactant in the solution becomes equal to the consumption rate at the electrode and a steady state is obtained: the current is entirely controlled by the rate of the chemical reaction. In the voltammogram, after reaching the maximum value, the current becomes constant and a wave instead of a peak appears.

In some cases, electrolysis can cause a decrease of the bulk concentration of the reagent (limited diffusion). It can be expected, that the main effect is a more rapid decay of the current after reaching the top of the peak (faster than the usual $t^{-1 / 2}$ relationship). Also, a decrease of the scan rate leads to a faster decrease of the peak current, again resulting in deviations from the linear $i-v^{1 / 2}$ dependence. In the extreme situation when the reagent is completely consumed, the equivalent amount of charge passes through the electrode: in such a case, the peak height becomes linearly dependent on the scan rate. In situations when mixed linear and limited diffusion occurs, transition from a proportionality to $v$ to a proportionality to $v^{1 / 2}$ could be observed.

If the reactant is strongly adsorbed on the electrode forming a mono- or a submonolayer on its surface and the adsorption equilibrium is rapidly reached, the situation resembles the extreme form of limited diffusion. The amount of substance is limited and it is available directly in the place where the electron transfer occurs, so no transport is necessary. The charge consumed in the reaction is constant, dependent only on the amount of substance and independent of scan rate. The result is a symmetric, sharp voltammetric peak, whose height is proportional to the scan rate; the width of the peak can be very small, because it is related to the variation of the adsorption energy with the electrode potential [7]. Theoretical studies of adsorption in voltammetry were done by several authors (see for example $[7,14,15])$.

Also useful is the dependence of the peak current and peak shape on the concentration. In principle, when the electron transfer is preceded by a first-order (or pseudo-first order) homogeneous process with respect to the electron transfer substrate or if there is no preceding step, the peak height should change linearly with the concentration. The situation differs, when the reaction is of higher order, but that case is not considered here. When adsorption occurs, the limited capacity of the monolayer causes a characteristic "saturation" effect: above a certain value of the bulk concentration, the peak height stabilizes and becomes independent of the concentration.

Convolution voltammetry facilitates the interpretation of SCV curves, particularly the information included in the peak shape. In the simplest case of semi-infinite linear diffusion and fast electron transfer, the convolution of the voltammetric current with a $t^{-1 / 2}$ decay results in an S-shaped wave [16-18]. Other mechanisms have been discussed in a number of papers [19-23].

When the transport to the electrode is enhanced or diminished compared to semi-infinite linear diffusion, the plateau of this wave has positive or negative slope, respectively. In this latter case, a "badly formed" peak is obtained. This method was applied in the detection of adsorption [24]. In this manner the problem of the detection of decreased flux can be reduced to finding peaks in semi-integral voltammograms.

To extend this test to processes in which the transport is larger than semi-infinite linear diffusion, a mathematical trick can be made: instead of semi-integration, integration to slightly lower order (e.g., 0.45-integration) can be used. In such a transformation, all voltammetric peaks for which 
the transport is as fast as or slower than linear diffusion, are converted to "badly formed" peaks or waves, while others are only partially broadened. Comparing peaks visible on the original, the 0.45-integrated and the semi-integrated voltammogram it is possible to classify them with respect to the type of the transport.

The criteria described above are very simple, but they have an important limitation: all waves obtained in convoluted voltammograms overlap, i.e., every subsequent one rises from the plateau of the previous wave. The bias of one plateau is taken over by all following waves, making them difficult to interpret. Due to this feature, simple classification gives reasonable results for the first peak in the forward branch of the voltammogram only.

To reduce the risk of an error in the determination of factors controlling the transport, a combination of criteria employing all three techniques (chronocoulometry, staircase voltammetry and convolution voltammetry) is used. The validity of the obtained results is subject to different restrictions. The general one is that different types of transport are always treated as different types of deviations from the semi-infinite linear diffusion model, but in order to detect them the magnitude of the deviation has to be significant.
This implies, that the hypothesis about the linear diffusion model is the default one and, to some extent, preferred: if there is no significant reason to reject it, it is accepted. Another limitation concerns overlapping signals: when more than one electrode process takes place at the given potential with a comparable rate, criteria for the determination of the transport type may deliver results for an averaged effect.

In Table 2, the diagnostic criteria used for the determination of factors controlling the flux of the electroactive substance are collected.

\section{NEW RULES}

A common feature of rules for all new mechanisms is that they are largely based on the correlation of the measured currents with the variation of experimental parameters, as well as on the changes in the current ratios with the time scale of the experiment. The new rules cover mechanisms collected in Table 3.

\section{ECE mechanisms}

This group consists of 18 variants of ECE mechanisms, differing in the reversibility of electrochemical and chemical steps. Criteria used are

\section{TABLE 2}

Diagnostic criteria for the determination of the type of transport to the electrode (Criteria within one set of columns, separated by vertical lines, are joined by the AND operator; between separated columns OR operator is used. Acronyms of dependences: $\mathrm{IV}=i_{p} / v^{1 / 2}$ vs. $v, \mathrm{IC}=i_{p} / C$ vs. $C, \mathrm{DIV}=\left(\mathrm{d}^{1 / 2} i / \mathrm{d} t^{1 / 2}\right) / v$ vs. $v, \mathrm{DIC}=\left(\mathrm{d}^{1 / 2} i / \mathrm{d} t^{1 / 2}\right) / C$ vs. $C ;\left(\mathrm{d}^{1 / 2} i / \mathrm{d} t^{1 / 2}\right)$ is a current semiderivative)

\begin{tabular}{|c|c|c|c|c|c|c|c|c|c|c|}
\hline \multirow[t]{2}{*}{ Transport type } & \multirow[t]{2}{*}{$Q$ vs. $t^{1 / 2}$} & \multirow[t]{2}{*}{$\mathrm{d} Q / \mathrm{d}\left(t^{-1 / 2}\right)$} & \multicolumn{4}{|c|}{$\begin{array}{l}\text { Peak in convolution } \\
\text { voltammetry }\end{array}$} & \multicolumn{4}{|c|}{$\begin{array}{l}\text { Trend in the absolute } \\
\text { value of }\end{array}$} \\
\hline & & & 0.5 & 0 & -0.45 & -0.5 & IV & IC & DIV & DIC \\
\hline From adsorbed state (ADS) & Nonlinear & Decrease & yes & yes & yes & yes & Incr. & Decr. & & \\
\hline $\begin{array}{l}\text { Mixed limited-linear } \\
\text { diffusion (LIM-LIN) }\end{array}$ & Nonlinear & Decrease & yes & yes & yes & yes & Decr. & Const. & & \\
\hline $\begin{array}{l}\text { Mixed adsorption-linear } \\
\text { diffusion (ADS-LIN) }\end{array}$ & Linear & Constant & yes & yes & yes & yes & Incr. & Not incr. & & \\
\hline $\begin{array}{l}\text { Semi-infinite linear } \\
\text { diffusion (LIN) }\end{array}$ & Linear & Constant & yes & yes & yes & no & Const. & Const. & Const. & Const. \\
\hline $\begin{array}{l}\text { Mixed linear and kinetic } \\
\text { effect (LIN-KIN) } \\
\text { Totally kinetic (KIN) }\end{array}$ & $\begin{array}{l}\text { Nonlinear } \\
\text { Nonlinear }\end{array}$ & $\begin{array}{l}\text { Increase } \\
\text { lncrease }\end{array}$ & $\begin{array}{l}\text { yes } \\
\text { yes }\end{array}$ & $\begin{array}{l}\text { yes } \\
\text { no }\end{array}$ & $\begin{array}{l}\text { no } \\
\text { no }\end{array}$ & $\begin{array}{l}\text { no } \\
\text { no }\end{array}$ & $\begin{array}{l}\text { Decr. } \\
\text { Decr. }\end{array}$ & $\begin{array}{l}\text { Const. } \\
\text { Const. }\end{array}$ & & \\
\hline
\end{tabular}

\footnotetext{
a Numbers describe instances of so-called differintegration (generalized differentiation and integration operation): $0.5=$
} semiderivative, $0-$ original voltammogram, $-0.45=0.45$-integration, $-0.5=$ semi-integration. 
the number of signals observed under various circumstances, their interrelation, the presence of a net reaction, characteristics of the separate reduction and oxidation signals and the ratio of heights of semiderivative peaks (see Table 4). Taking into account that there are at least four compounds involved in the entire reaction scheme

$A_{1} \stackrel{e}{\Leftrightarrow} B_{1} \Leftrightarrow A_{2} \stackrel{e}{\Leftrightarrow} B_{2}$

it can be generally expected, that signals of the four processes: $A_{1} \rightarrow B_{1}, B_{1} \rightarrow A_{1}, A_{2} \rightarrow B_{2}$ and $B_{2} \rightarrow A_{2}$ should be observed. The actual number of observable signals is, however, influenced by the characteristics (e.g., irreversibility) of reactions taking place. In principle, the process $A_{1} \rightarrow$ $B_{1}$ is of EC type, whereas $A_{2} \rightarrow B_{2}$ should exhibit some similarities with $C E$ reaction.

A useful criterion in the elucidation of ECE mechanisms is the appearance of an additional peak (secondary peak) in the third branch of the voltammogram. Such peaks can be observed if the standard potential of the reversible second electron transfer step is less extreme than that of the first charge transfer; they originate from the $A_{2}$ intermediate produced during the second half-cycle.

In the elucidation of ECE mechanisms, the relative heights of voltammetric peaks play an important role [24]. However, the determination of these parameters in the case of an ECE process is likely to be difficult, or even impossible, due to the overlap of SCV peak tails. To avoid this problem, rules in this expert system make use of semiderivative voltammetry: with its narrower peaks with easily measurable heights this technique is advantageous. The chance of overlap is significantly reduced and results for peak heights are much more reliable.

Table 4 collects criteria for the elucidation of ECE mechanisms.

There is a number of restrictions for the applicability of the above criteria: generally, if the chemical step is very fast, an ECE mechanism is indistinguishable from EE. Additionally, the possibility of cross-reaction (disproportionation) has been neglected in the present rules.

\section{Mechanisms with adsorption}

Four simple cases of uncomplicated electron transfer are considered here, where adsorption (either strong or weak) of substrate or product takes place. Rules are based on the paper by Wopschall and Shain [25]. In the case of strong adsorption, two peaks in each branch can be observed; if the adsorption is weak, only one peak with a characteristic shape can be found in each branch.

Elucidation criteria (see Table 5) are primarily based on the determination of factors controlling the transport to the electrode, among others on the characteristic dependence of adsorptive peak height on the scan rate in voltammetry. This latter feature is also exploited in criteria involving peak height ratios.

It should be emphasized, that above criteria are valid under the assumption, that no complications accompany the electron transfer step and the rate of adsorption is very high compared to the time scale of the experiment. It is also assumed, that no competitive adsorption (for instance of the substrate and the product of the electrode reaction) takes place.

\section{EE Mechanisms}

This group covers four combinations of two electron transfer steps, where each step can be either fast or irreversible (ErEr, ErEi, EiEr and $\mathrm{EiEi}$ ) and one special case of ErEs mechanism with $E_{2}^{0^{\prime}} \ll E_{1}^{0^{\prime}}$. There is no coupled homogeneous chemical process and no adsorption takes place.

The variation of potentials of both processes with scan rate should follow patterns predicted for electron transfers with an uncomplicated character.

The most crucial step in proving the EE mechanisms is the exclusion of the chemical reaction intervening the electron transfer steps. If the substrate of the second step is produced in a chemical step, the relative height of peak 2 with respect to peak 1 in the forward branch of the semiderivative voltammogram increases with a decrease of the scan rate. If there is no intermediate chemical reaction, such an effect does not occur and the ratio of peak heights is constant. 
The difference between the ECE and EE mechanism is also manifest in a different type of transport for the first and the second signal in the ECE mechanism, while in the EE mechanism the type of transport is the same. It is, however, impossible to exclude the presence of a very fast chemical reaction between steps 1 and 2 . Such a reaction has no visible effects in the time scale of the experiment and, as already mentioned in the part concerning the ECE mechanism, ECE and EE mechanisms would not be distinguishable under such circumstances.

Table 6 lists criteria used to elucidate EE mechanisms.

\section{TABLE 3}

List of additional mechanisms, that can be elucidated by the expert system (Symbols: $E=$ electron transfer step, $C=$ chemical step, $\mathrm{A}=$ adsorption, " $\Leftrightarrow$ " and $" \stackrel{\varsigma}{\rightarrow}$ " = reversible and irreversible electr. transfer, " $\Leftrightarrow$ " and " $\rightarrow$ " = reversible and irreversible chemical reaction)

\begin{tabular}{|c|c|c|}
\hline Symbol & Reaction & Description \\
\hline ErCrEr & $A \& B \Leftrightarrow C \& D$ & $\begin{array}{l}\text { ECE reaction with both electron transfers fast and reversible chemical step; } \\
\text { three cases: } E_{2}^{0^{\prime}} \ll E_{1}^{0^{\prime}}, E_{2}^{0^{\prime}} \approx E_{1}^{0^{\prime}} \text { and } E_{2}^{0^{\prime}} \rightarrow E_{1}^{0^{\prime}}\end{array}$ \\
\hline ErCiEr & 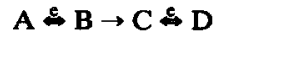 & $\begin{array}{l}\text { ECE reaction with both electron transfers fast and irreversible chemical step; } \\
\text { three cases: } E_{2}^{0^{\prime}} \ll E_{1}^{0^{\prime}}, E_{2}^{0^{\prime}} \approx E_{1}^{0^{\prime}} \text { and } E_{2}^{0^{\prime}} \rightarrow E_{1}^{0^{\prime}}\end{array}$ \\
\hline $\mathrm{ErCrEi}$ & $A \stackrel{c}{\Leftrightarrow} B \Leftrightarrow C \stackrel{e}{\rightarrow} D$ & $\begin{array}{l}\text { ECE reaction with the first } \mathrm{E} \text { step fast, the second one, irreversible and reversible } \mathrm{C} \\
\text { step. Three cases: } E_{2}^{0^{\prime}} \ll E_{1}^{0^{\prime}}, E_{2}^{0^{\prime}} \approx E_{1}^{0^{\prime}} \text { and } E_{2}^{0^{\prime}} \gg E_{1}^{0^{\prime}}\end{array}$ \\
\hline ErCiEi & $A \stackrel{c}{\leftrightarrows} B \rightarrow C \stackrel{c}{\rightarrow} D$ & $\begin{array}{l}\text { ECE reaction with the first } \mathrm{E} \text { step fast, the second one, irreversible and irreversible } \\
\text { chemical reaction. Three cases: } E_{2}^{0^{\prime}} \ll E_{1}^{0^{\prime}}, E_{2}^{0^{\prime}} \approx E_{1}^{0^{\prime}} \text { and } \nabla_{2}^{0^{\prime}} \rightarrow E_{1}^{0^{\prime}}\end{array}$ \\
\hline EiCEr & $\begin{array}{l}A \stackrel{c}{\rightarrow} B \Leftrightarrow C \stackrel{\&}{\Leftrightarrow} D \text { or } \\
A \stackrel{e}{\rightarrow} B \rightarrow C \stackrel{\Leftrightarrow}{\Leftrightarrow} D\end{array}$ & $\begin{array}{l}\text { ECE reaction with the first electron transfer irreversible and the second one, fast, } \\
\text { three cases: } E_{2}^{0^{\prime}} \ll E_{1}^{0^{\prime}}, E_{2}^{0^{\prime}} \approx E_{1}^{0^{\prime}} \text { and } E_{2}^{0^{\prime}} \rightarrow E_{1}^{0^{\prime}}\end{array}$ \\
\hline EiCEi & $\begin{array}{l}A \stackrel{c}{\rightarrow} B \Leftrightarrow C \stackrel{c}{\rightarrow} D \text { or } \\
A \stackrel{c}{\rightarrow} B \rightarrow C \stackrel{c}{\rightarrow} D\end{array}$ & $\begin{array}{l}\text { ECE reaction with both electron transfers irreversible, three cases: } \\
E_{2}^{0^{\prime}} \ll E_{1}^{0^{\prime}}, E_{2}^{0^{\prime}} \approx E_{1}^{0^{\prime}} \text { and } E_{2}^{0^{\prime}} \gg E_{1}^{0^{\prime}}\end{array}$ \\
\hline EAs & $\mathrm{A} \Leftrightarrow \mathrm{B}^{*}$ & Fast electron transfer with a fast, strong adsorption of the product \\
\hline EAw & 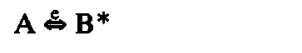 & Fast electron transfer with a fast, weak adsorption of the product \\
\hline AsE & $A^{*} \& B$ & Fast electron transfer with a fast, strong adsorption of the substrate \\
\hline AwE & $\mathrm{A}^{*} \stackrel{\mathrm{c}}{\mathrm{B}}$ & Fast electron transfer with a fast, weak adsorption of the substrate \\
\hline ErEr & $A \& B \Leftrightarrow C$ & Uncomplicated double-step electron transfer, both steps fast, $E_{2}^{0^{\prime}} \ll E_{1}^{0^{\prime}}$ \\
\hline ErEs & $A \Leftrightarrow B \& C$ & $\begin{array}{l}\text { Uncomplicated double-step electron transfer, the first step fast, the second one slow, } \\
E_{2}^{0^{\prime}} \ll E_{1}^{0^{\prime}}\end{array}$ \\
\hline ErEi & $\mathrm{A} \stackrel{e}{\Leftrightarrow} \mathrm{B} \stackrel{e}{\rightarrow} \mathrm{C}$ & $\begin{array}{l}\text { Uncomplicated double-step electron transfer, the first step fast, the second one } \\
\text { irreversible, } E_{2}^{0^{\prime}} \ll E_{1}^{0^{\prime}}\end{array}$ \\
\hline EiEr & $\mathrm{A} \stackrel{\mathrm{e}}{\rightarrow} \mathrm{B} \Leftrightarrow \mathrm{C}$ & $\begin{array}{l}\text { Uncomplicated double-step electron transfer, the first step irreversible, the second one } \\
\text { fast, } E_{2}^{0^{\prime}} \ll E_{1}^{0^{\prime}}\end{array}$ \\
\hline $\mathrm{EiEi}$ & $A \stackrel{c}{\rightarrow} B \stackrel{e}{\rightarrow} C$ & Uncomplicated double-step electron transfer, both step irreversible, $E_{2}^{0^{\prime}} \ll E_{1}^{0^{\prime}}$ \\
\hline $\mathbf{E} \Leftrightarrow \mathbf{E}$ & 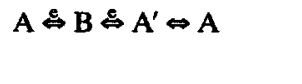 & $\begin{array}{l}\text { "Triangle scheme": electron transfers fast, chemical reaction reversible, } \\
\text { large difference in formal potentials }\end{array}$ \\
\hline $\mathrm{E} \Leftrightarrow \mathrm{E}$ & $A \Leftrightarrow B \Leftrightarrow B^{\prime} \Leftrightarrow A^{\prime} \Leftrightarrow A$ & $\begin{array}{l}\text { "Square scheme": electron transfers fast, chemical reaction reversible, } \\
\text { large difference in formal potentials }\end{array}$ \\
\hline
\end{tabular}


"Square" and "triangle" scheme mechanisms

In this case two different forms of the electroactive compound, remaining in a chemical equilibrium, can react giving either two different products or only one product. It is taken for granted that electron transfer steps (ETS) are not irreversible, that the differences of potentials at which electron transfer steps occur are significant and that all signals can be observed separately. The overall scheme of reaction can be written as

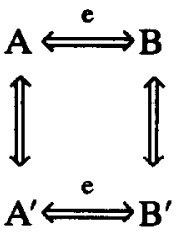

TABLE 4

Diagnostic criteria for ECE mechanisms (Acronyms: $F=$ signal in the forward branch, $B=$ signal in the backward branch of the voltammogram, HS $=$ hidden signals (see [2], $\mathbf{S S}=$ secondary signals, $\mathbf{N R}=$ net reaction, $\mathbf{S M S}=$ suggestion of mechanism of the electron transfer, RSDH = ratio of semiderivative peak heights)

\begin{tabular}{|c|c|c|c|c|c|c|c|c|c|}
\hline $\begin{array}{l}\text { Mecha- } \\
\text { nism }\end{array}$ & $\begin{array}{l}\text { Relation } \\
E_{2}^{0^{\prime}} / E_{1}^{0^{\prime}}\end{array}$ & $\begin{array}{l}\text { Number } \\
\text { of } F, B\end{array}$ & HS & SS & $\begin{array}{l}\text { Signal as- } \\
\text { signment }\end{array}$ & NR & $\begin{array}{l}\text { Type of the transport } \\
\text { (see Table 2) }\end{array}$ & SMS & $\begin{array}{l}\text { Absolute trend } \\
\text { in RSDH }\end{array}$ \\
\hline $\mathrm{ErCrEr}$ & $E_{2}^{0^{\prime}} \ll E_{1}^{0^{\prime}}$ & 2,2 & no & no & $\begin{array}{l}\mathrm{B} 1 \rightarrow \mathrm{F} 1 \\
\mathrm{~B} 2 \rightarrow \mathrm{F} 2\end{array}$ & no & $\begin{array}{l}\text { F1: LIN } \\
\text { F2: LIN-KIN }\end{array}$ & F1: ECr & $\begin{array}{l}\text { B1/F1 const } \\
\text { F2/F1: decr } \\
\text { B2/B1: decr }\end{array}$ \\
\hline $\mathrm{ErCrEr}$ & $E_{2}^{0^{\prime}} \approx E_{1}^{0^{\prime}}$ & 1,1 & no & no & & no & $\begin{array}{l}\text { F1: LIN-KIN } \\
\text { F2: LIN-KIN }\end{array}$ & & B1/F1: const \\
\hline $\mathrm{ErCrEr}$ & $E_{2}^{0^{\prime}} \rightarrow E_{1}^{0^{\prime}}$ & 1,2 & no & yes & & no & F1: LIN-KIN & B1: $\mathrm{E}$ or $\mathrm{CEr}$ & $\begin{array}{l}\text { B2/F2: incr } \\
\text { B2/F1 incr }\end{array}$ \\
\hline $\mathrm{ErCiEr}$ & $E_{2}^{0^{\prime}} \ll E_{1}^{0^{\prime}}$ & 2,2 & no & no & $\begin{array}{l}\mathrm{B} 1 \rightarrow \mathrm{F} 1 \\
\mathrm{~B} 2 \rightarrow \mathrm{F} 2\end{array}$ & yes & $\begin{array}{l}\text { F1: LIN } \\
\text { F2: LIN-KIN }\end{array}$ & F1: ECi & $\begin{array}{l}\text { B1/F1: incr } \\
\text { B2/B1: decr } \\
\text { B1/F1: const }\end{array}$ \\
\hline $\mathrm{ErCiEr}$ & $E_{2}^{0^{\prime}} \approx E_{1}^{0^{\prime}}$ & 1,1 & no & no & & yes & $\begin{array}{l}\text { F1: LIN-KIN } \\
\text { F2: LIN-KIN }\end{array}$ & & B1/F1: incr \\
\hline ErCiEr & $E_{2}^{0^{\prime}} \gg E_{1}^{0^{\prime}}$ & 1,2 & no & no & & yes & F1: LIN-KIN & B1: E or CEr & $\begin{array}{l}\text { B2/F2: incr } \\
\text { B2/F1 incr }\end{array}$ \\
\hline $\mathrm{ErCrEi}$ & $E_{2}^{0^{\prime}} \ll E_{1}^{0^{\prime}}$ & 2,1 & no & no & $\mathrm{B} 1 \rightarrow \mathrm{F} 1$ & yes & $\begin{array}{l}\text { F1: LIN } \\
\text { F2: LIN-KIN }\end{array}$ & F1: ECr & $\begin{array}{l}\text { F2/F1: decr } \\
\text { B1/F1: incr }\end{array}$ \\
\hline ErCrEi & $E_{2}^{0^{\prime}} \approx E_{1}^{0^{\prime}}$ & 1,1 & no & no & & yes & $\begin{array}{l}\text { F1: LIN-KIN } \\
\text { B1: LIM-LIN }\end{array}$ & & $\mathrm{B} 2 / \mathrm{F} 1$ : incr \\
\hline $\mathrm{ErCrEi}$ & $E_{2}^{0^{\prime}} \gg E_{1}^{0^{\prime}}$ & 1,1 & no & no & & yes & $\begin{array}{l}\text { F1: LIN-KIN } \\
\text { B1: LIM-LIN }\end{array}$ & & B2/F1: incr \\
\hline $\mathrm{ErCiEi}$ & $E_{2}^{0^{\prime}} \ll E_{1}^{0^{\prime}}$ & 2,1 & no & no & $\mathrm{B} 1 \rightarrow \mathrm{F} 1$ & yes & $\begin{array}{l}\text { F1: LIN } \\
\text { F2: LIN-KIN }\end{array}$ & F1: ECi & $\begin{array}{l}\text { F2/F1: decr } \\
\text { B1/F1: incr }\end{array}$ \\
\hline ErCiEi & $E_{2}^{0^{\prime}}=E_{1}^{0^{\prime}}$ & 1,1 & no & no & & yes & $\begin{array}{l}\text { F1: LIN-KIN } \\
\text { B1: LIM-LIN }\end{array}$ & & $\mathrm{B} 2 / \mathrm{F} 1$ : incr \\
\hline ErCiEi & $E_{2}^{0^{\prime}} \rightarrow E_{1}^{0^{\prime}}$ & 1,1 & no & no & & yes & $\begin{array}{l}\text { F1: LIN-KIN } \\
\text { B1: LIM-LIN }\end{array}$ & & B2/F1: incr \\
\hline EiCEr & $E_{2}^{0^{\prime}} \ll E_{1}^{0^{\prime}}$ & 2,1 & no & no & & yes & $\begin{array}{l}\text { F1: LIN } \\
\text { F2: LIN-KIN }\end{array}$ & & $\begin{array}{l}\text { F2/F1: decr } \\
\text { B2/F1: decr }\end{array}$ \\
\hline EiCEr & $E_{2}^{0^{\prime}} \approx E_{1}^{0^{\prime}}$ & 1,1 & no & no & & yes & $\begin{array}{l}\text { F1: LIN-KIN } \\
\text { F2: LIN-KIN }\end{array}$ & & B1/F1: decr \\
\hline EiCEr & $E_{2}^{0^{\prime}} \gg E_{1}^{0^{\prime}}$ & 1,1 & no & yes & & yes & F1: LIN-KIN & & \\
\hline EiCEi & $E_{2}^{0^{\prime}} \ll E_{1}^{0^{\prime}}$ & 2,0 & no & no & & & $\begin{array}{l}\text { F1: LIN } \\
\text { F2: LIN-KIN }\end{array}$ & & B1/F1: decr \\
\hline $\begin{array}{l}\text { EiCEi } \\
\text { EiCEi }\end{array}$ & $\begin{array}{l}E_{2}^{0^{\prime}} \approx E_{1}^{0^{\prime}} \\
E_{2}^{0^{\prime}}>E_{1}^{0^{\prime}}\end{array}$ & $\begin{array}{l}1,0 \\
1,0\end{array}$ & $\begin{array}{l}\text { no } \\
\text { no }\end{array}$ & $\begin{array}{l}\text { no } \\
\text { no }\end{array}$ & & & $\begin{array}{l}\text { F1: LIN-KIN } \\
\text { F1: LIN-KIN }\end{array}$ & & \\
\hline
\end{tabular}




\section{TABLE 5}

Diagnostic criteria for single mechanisms with adsorption $(\mathrm{F}=$ Signal in the forward branch, $\mathrm{B}=$ signal in the backward branch of the voltammogram, HS = hidden signals (see [2]), SS = secondary signals, DDPH = difference of semiderivative peak height vs. scan rate)

\begin{tabular}{|c|c|c|c|c|c|}
\hline Mechanism & Number of F, B & HS & SS & Type of the transport & Trend in DDPH \\
\hline EAs & $\begin{array}{l}2,2 \\
1,1\end{array}$ & $\begin{array}{l}\text { no } \\
\text { yes }\end{array}$ & no & $\begin{array}{l}\text { F1: ADS } \\
\text { B1: ADS }\end{array}$ & $\begin{array}{l}\text { F1-F2 decrease } \\
\text { B1-B2 increase }\end{array}$ \\
\hline EAw & 1,1 & no & no & $\begin{array}{l}\text { F1: LIN } \\
\text { B1: ADS-LIN }\end{array}$ & \\
\hline AsE & $\begin{array}{l}2,2 \\
1,1\end{array}$ & $\begin{array}{l}\text { no } \\
\text { yes }\end{array}$ & no & $\begin{array}{l}\text { F1: LIN } \\
\text { B1: LIN or LIN-KIN }\end{array}$ & $\begin{array}{l}\mathrm{F} 1-\mathrm{F} 2 \text { increase }^{\mathrm{a}} \\
\mathrm{B} 1-\mathrm{B} 2 \text { decrease }^{\mathrm{a}}\end{array}$ \\
\hline AwE & 1,1 & no & no & $\begin{array}{l}\text { F1: ADS-LIN } \\
\text { B1: LIN or LIN-KIN }\end{array}$ & \\
\hline
\end{tabular}

a For reduction in forward branch and oxidation in backward one; otherwise trends should be reversed.

\section{TABLE 6}

Diagnostic criteria for double-step mechanisms (Acronyms: $F=$ signal in the forward branch, $B=$ signal in the backward branch of the voltammogram, HS = hidden signals (see [2]), SS = secondary signals, NR = net reaction, SMS = suggestion of mechanism of the electron transfer, $R D P H=$ ratio of semiderivative peak heights, DDPP = difference of semiderivative peak potentials)

\begin{tabular}{|c|c|c|c|c|c|c|c|c|c|}
\hline $\begin{array}{l}\text { Mecha- } \\
\text { nism }\end{array}$ & $\begin{array}{l}\text { Number } \\
\text { of F, B }\end{array}$ & HS & SS & $\begin{array}{l}\text { Peak as- } \\
\text { signment }\end{array}$ & NR & $\begin{array}{l}\text { Type of } \\
\text { transport }\end{array}$ & SMS & $\begin{array}{l}\text { Trend in } \\
\text { RDPH }\end{array}$ & Trend in DDPP \\
\hline ErEr & 2,2 & no & no & $\begin{array}{l}\mathrm{F} 1 \rightarrow \mathrm{B} 1, \\
\mathrm{~F} 2 \rightarrow \mathrm{B} 2\end{array}$ & no & $\begin{array}{l}\text { F1: LIN } \\
\text { F2: LIN }\end{array}$ & all $\mathrm{E}$ & F2/F1: const. & $\begin{array}{l}\text { F1-B1: const. } \\
\text { F2-B2: const. }\end{array}$ \\
\hline ErEs & 2,2 & no & no & $\mathrm{F} 1 \rightarrow \mathrm{B} 1$ & no & $\begin{array}{l}\text { F1: LIN } \\
\text { F2: LIN }\end{array}$ & $\begin{array}{l}\text { F1: E } \\
\text { B1: E }\end{array}$ & F2/F1: const. & $\begin{array}{l}\text { F1-B1: const. } \\
\text { F2-B2: not const. }\end{array}$ \\
\hline $\mathrm{ErEi}$ & 2,1 & no & no & $\mathrm{F} 1 \rightarrow \mathrm{B} 1$ & yes & all LIN & $\begin{array}{l}\text { F1: E } \\
\text { F2: Es } \\
\text { B1: E }\end{array}$ & F2/F1: const. & F1-B1: const. \\
\hline EiEr & 2,1 & no & no & $\mathrm{F} 2 \rightarrow \mathrm{B} 1$ & yes & all LIN & $\begin{array}{l}\text { F1: Es } \\
\text { F2: E } \\
\text { B1: E }\end{array}$ & F2/F1: const. & F2-B1: const. \\
\hline $\mathrm{EiEi}$ & 2,0 & no & no & & & all LIN & all E & F2/F1: const. & \\
\hline
\end{tabular}

\section{TABLE 7}

Diagnostic criteria for triangle and square scheme mechanisms (F = Signal in the forward branch, $B=$ signal in the backward branch of the voltammogram, HS = hidden signals (see [2]), SS = secondary signals, RDPH = ratio of semiderivative peak heights, $\mathrm{SPH}=$ semiderivative peak height, $i_{\mathrm{p}}=\mathrm{SCV}$ peak height)

\begin{tabular}{|c|c|c|c|c|c|c|c|}
\hline \multirow[t]{2}{*}{ Mechanism } & \multirow{2}{*}{$\begin{array}{l}\text { Number } \\
\text { of F, B }\end{array}$} & \multirow[t]{2}{*}{ HS } & \multirow[t]{2}{*}{ SS } & \multirow{2}{*}{$\begin{array}{l}\text { type of } \\
\text { transport }\end{array}$} & \multicolumn{2}{|l|}{ Trend in } & \multirow[t]{2}{*}{$\mathrm{d}\left(i_{\mathrm{p}} / C\right) \mathrm{d} C$ value } \\
\hline & & & & & RDPH & $\overline{\mathrm{d}(\mathrm{SPH} / C) \mathrm{d} C \text { Value }}$ & \\
\hline $\mathbf{E} \Leftrightarrow \mathbf{E}$ & 2,1 & no & no & $\begin{array}{l}\text { F1: LIN-KIN } \\
\text { B1: LIN-KIN }\end{array}$ & F2/F1 incr ${ }^{a}$ & $\begin{array}{l}\text { F1: const. } \\
\text { F2: const. }\end{array}$ & $\begin{array}{l}\text { F1: } 0.0 \\
\text { F2: } 0.0\end{array}$ \\
\hline $\mathbf{E} \Leftrightarrow \mathrm{E}$ & 2,2 & no & no & $\begin{array}{l}\text { F1: LIN-KIN } \\
\text { B1: LIN-KIN }\end{array}$ & $\mathbf{F} 2 / \mathbf{F} 1$ incr $^{a}$ & $\begin{array}{l}\text { F1: const. } \\
\text { F2: const. }\end{array}$ & $\begin{array}{l}\text { F1: } 0.0 \\
\text { F2: } 0.0\end{array}$ \\
\hline
\end{tabular}

a For the reduction in forward and the oxidation in the backward branch; otherwise trend is reverse. 
or<smiles>[Y]1[CH][Te][Te]1</smiles>

A general discussion of this type of reaction has been presented by Ashley and Reilley [26]. It is assumed, that the chemical steps proceed according to first-order kinetics and are reversible; additionally it is assumed, that the electron transfer steps are very fast.

The diagnostic criteria (Table 7) take advantage of the fact, that depletion of the diffusion zone for one substrate, say A, induces its production from $A^{\prime}$ in the chemical reaction thus enhancing the transport to the electrode. However, the consumption of $A^{\prime}$ causes a reduction of the corresponding $\mathrm{A}^{\prime} \rightarrow \mathrm{B}^{\left(^{\prime}\right)}$ signal (lower peak in SCV and semiderivative voltammetry), this effect being more pronounced for slower scan rates. This results in an increase of the height ratio of the second to the first peak of the forward branch with the scan rate.

The criteria from Table 7 will not apply if the chemical reactions are irreversible, if they have other than first-order kinetics and if their rates are very high or very low compared to the time scale of the experiment.

\section{VALIDATION}

To validate the modified and the newly added rules, a number of compounds for which reaction mechanisms are already established have been studied. The selected electrochemical systems were mixture of $\mathrm{Zn}^{2+}$ and $\mathrm{Cd}^{2+}$ ions, 2nitrophenol, 4-nitrosophenol and Methylene Blue. The mixture of zinc and cadmium ions was used to validate ErEs mechanism; for the expert system it is indistinguishable from a substance undergoing a double-step reduction.

For each system, validation results are collected in two tables: the first one presents support for separate features used as criteria to elucidate the pertaining mechanism, on the basis of Tables 4-7, and the list of possible mechanisms, ordered according to decreasing support. In the second table, for each mechanism the feature that had the strongest influence on the support is given. Because rules for the elucidation of mechanisms involve mainly conjunctions of features, the most influential feature is the one with the lowest supporting pair.

\section{Experimental}

Autolab-100 General Purpose Electrochemical System (Eco Chemie, Utrecht) coupled to an Olivetti M24 personal computer (IBM PC-compatible, $8086 \mathrm{cpu}$ and 8087 numerical coprocessor) were used to carry out experiments and to run the expert system. All measurements were made on the static mercury electrode (Metrohm VA-663), composition of the solution in the cell was controlled using two Dosimat 665 burettes (Metrohm) and a Metrohm 661 pump unit.

In all experiments, solutions were prepared with deionized water (Millipore Q2). Oxygen was expelled with polarographic grade nitrogen (Hoekloos, Netherlands). Mercury for the filling of the electrode (commercial grade), has been successively purified by shaking with ethanol, $2 \mathrm{M}$ sodium hydroxide and $2 \mathrm{M}$ nitric acid and finally doubly distilled at low pressure.

$0.05 \mathrm{M}+0.05 \mathrm{M}$ solutions of cadmium chloride (Merck, Suprapur) and of zinc sulphate (Fluka, p.a.) were prepared by the dissolution of respective salts in $1 \mathrm{M} \mathrm{KCl}$ (Suprapur). Methylene Blue (for electrophoresis, Merck) was dissolved in $80 \% \quad 0.1 \mathrm{M}$ boric acid- $\mathrm{KCl}-\mathrm{NaOH}$ buffer (pH 10.0, Merck) mixed with 20 vol.\% ethanol (Merck). The solution of $p$-nitrosophenol (Aldrich) was prepared in $0.1 \mathrm{M} \mathrm{KNO}_{3}$ containing $0.067 \mathrm{M}$ acetate buffer (pH 4.66, Merck) and $20 \%$ ethanol. The stock solution of $o$-nitrophenol (p.a., Fluka) was obtained by the dissolution of the compound in $0.1 \mathrm{M} \mathrm{CH}_{3} \mathrm{COOH}+0.1 \mathrm{M}$ $\mathrm{CH}_{3} \mathrm{COONa}$ buffer mixed with ethanol (50 vol. \%).

All potentials were measured in respect to $\mathrm{Ag} / \mathrm{AgCl}$ (3 $\mathrm{M} \mathrm{KCl}$ ) reference electrode (Metrohm). As auxiliary electrode a glassy carbon rod was used. 
During the experiments with the $\mathrm{Cd}^{2+}$ and $\mathrm{Zn}^{2+}$ ions mixture, the concentration in the electrochemical cell was varied from $0.8 \times 10^{-4}$ to $2.6 \times 10^{-4} \mathrm{~mol} \mathrm{dm}^{-3}$ and the range of scan rates used in voltammetric measurements was from $0.25 \mathrm{~V} \mathrm{~s}^{-1}$ up to $10.0 \mathrm{~V} \mathrm{~s}^{-1}$. The potential was scanned in the range -0.3 to $-1.45 \mathrm{~V}$. In chronocoulometric experiments, the conditioning period of $1 \mathrm{~s}$ at $-0.3 \mathrm{~V}$ was followed by two potential steps, respectively -0.8 and $-0.3 \mathrm{~V}$, with a duration of $0.4 \mathrm{~s}$ each.

In cyclic voltammetry of Methylene Blue, the range of potentials of $-0.1 \mathrm{~V}$ to $-0.8 \mathrm{~V}$ was scanned with a rate that varied between 0.3 and
$1.6 \mathrm{~V} \mathrm{~s}^{-1}$. The concentration range investigated was $8.0 \times 10^{-5}$ to $2.6 \times 10^{-4} \mathrm{~mol} \mathrm{dm}^{-3}$. Chronocoulometric experiments were carried out in exactly the same time regime as for the cadmium + zinc mixture.

$p$-Nitrosophenol was investigated in the range of potentials from $+0.35 \mathrm{~V}$ to $-0.4 \mathrm{~V}$ using scan rates varying from $0.05 \mathrm{~V} \mathrm{~s}^{-1}$ to $2.15 \mathrm{~V} \mathrm{~s}^{-1}$. The concentration was changed from $2.0 \times 10^{-4}$ to $2.0 \times 10^{-3} \mathrm{~mol} \mathrm{dm}^{-3}$. In the chronocoulometric experiment, the duration of the steps was $1 \mathrm{~s}$ (preconditioning), $0.4 \mathrm{~s}$ and $0.4 \mathrm{~s}$ (potentials $+0.35 \mathrm{~V},-0.4 \mathrm{~V}$ and $+0.35 \mathrm{~V}$, respectively).

Voltammograms of $o$-nitrophenol were re-

TABLE 8

Features and their support obtained during the elucidation of the ErEs mechanism imitated by the reduction of a mixture of $\mathrm{Zn}^{2+}$ and $\mathrm{Cd}^{2+}$ ions in $\mathrm{KCl}$ solution (Acronyms: $\mathrm{F}=$ signal in the forward branch, $\mathrm{B}=$ signal in the backward branch)

\begin{tabular}{|c|c|c|c|}
\hline $\mathrm{F}=2, \mathrm{~B}=2$ & {$[1.000,1.000]$} & Assignment of peaks & \\
\hline Net reaction present & {$[0.000,1.1 \mathrm{E}-16]$} & $\mathrm{B} 1 \rightarrow \mathrm{F} 1, \mathrm{~B} 2 \rightarrow \mathrm{F} 2$ & {$[1.000,1.000]$} \\
\hline Suggestion for the type of th & (Table 4 in Ref. 2) & & \\
\hline F1: E & {$[0.469,0.613]$} & B1: E & {$[0.487,0.594]$} \\
\hline F1: ECr & {$[0.007,0.054]$} & B1: CEr & {$[0.018,0.159]$} \\
\hline F1: Es & {$[0.006,0.855]$} & B1: Es & {$[0.013,0.785]$} \\
\hline F1: EiCat & {$[1.1 \mathrm{E}-5,6.7 \mathrm{E}-5]$} & B1: EiCat & {$[0.012,0.079]$} \\
\hline F1: ECi, CEi & {$[8.5 \mathrm{E}-6,6.2 \mathrm{E}-5]$} & $\mathrm{B1}: \mathrm{ECi}, \mathrm{CEi}$ & {$[3.009,0.077]$} \\
\hline F1: ErCat & {$[2.2 \mathrm{E}-6,5.7 \mathrm{E}-5]$} & B1: CEr & {$[0.006,0.147]$} \\
\hline F1: CEr & {$[2.1 \mathrm{E}-6,5.5 \mathrm{E}-5]$} & B1: ECr & {$[0.000,0.000]$} \\
\hline F2: Es & {$[0.418,0.706]$} & B2: CEr & {$[0.536,0.666]$} \\
\hline F2: ECi, CEi & {$[0.398,0.636163]$} & B2: Es & {$[0.446,0.705]$} \\
\hline F2: EiCat & {$[0.1848,0.294]$} & B2: ErCat & {$[9.303,0.377]$} \\
\hline F2: E & {$[8.5 \mathrm{E}-7,0.265]$} & B2: EiCat & {$[0.303,0.377]$} \\
\hline F2: CEr & {$[0.000,0.238]$} & B2: E & {$[0.002,0.486]$} \\
\hline F2: ErCat & {$[0.000,0.110]$} & B2: ECi, CEi & {$[0.000,0.130]$} \\
\hline F2: ECr & {$[0.000,0.000]$} & $\mathrm{B} 2: \mathrm{ECr}$ & {$[0.000,0.000]$} \\
\hline Transport to the electrode & & B1: LIM-LIN & {$[0.995,0.995]$} \\
\hline F1: LIN & {$[0.890,0.890]$} & B1: ADS & {$[0.333,0.333]$} \\
\hline F1: LIN-KIN & {$[0.750,0.750]$} & B1: LIN & {$[0.227,0.227]$} \\
\hline F1: ADS-LIN & {$[0.001,0.001]$} & B1: LIN-KIN & {$[0.201,0.201]$} \\
\hline F1: other & {$[0.000,0.000]$} & B1: ADS-LIN & {$[0.001,0.001]$} \\
\hline & & B1: KIN & {$[0.000,0.000]$} \\
\hline F2: LIM-LIN & {$[1.000,1.600]$} & & \\
\hline F2: LIN & {$[1.000,1.000]$} & B2: LIM-LIN & {$[1.000,1.000]$} \\
\hline F2: LIN-KIN & {$[1.000,1.000]$} & B2: LIN & {$[1.000,1.000]$} \\
\hline F2: other & {$[0.000,0.000]$} & B2: LIN-KIN & {$[1.000,1.000]$} \\
\hline & & B2: other & {$[0.000,0.000]$} \\
\hline System mechanis & & & \\
\hline ErEs & {$[0.116,0.257]$} & & \\
\hline $\mathrm{ErCrEr}, \mathrm{E} 2 \ll 1$ & {$[4.0 \mathrm{E}-4,0.004]$} & & \\
\hline $\mathbf{E} \Leftrightarrow \mathbf{E}$ & {$[1.5 \mathrm{E}-25,0.000]$} & & \\
\hline other & {$[0.000,0.000]$} & & \\
\hline
\end{tabular}


corded in the range $+0.1 \mathrm{~V}$ to $-0.9 \mathrm{~V}$, with scan rate varying from 0.3 to $10.0 \mathrm{~V} \mathrm{~s}^{-1}$ and the concentration in the range $10^{-4}$ up to $10^{-3} \mathrm{~mol}$ $\mathrm{dm}^{-3}$. In chronocoulometric experiments, the potential was changed from $+0.1 \mathrm{~V}$ to $-0.9 \mathrm{~V}$ for 0.4 and $0.4 \mathrm{~s}$, respectively; the preconditioning pulse at $+0.1 \mathrm{~V}$ took $1 \mathrm{~s}$.

ErEs mechanism, reduction of $\mathrm{Cd}^{2+}$ and $\mathrm{Zn}^{2+}$ mixture in $\mathrm{KCl}$

A mixture of zinc and cadmium ions can imitate a substance that is reduced according to the ErEs mechanism. The difference can be detected by comparison of the products $n F A D^{1 / 2} C$ for the first and second steps (obtained either by chronocoulometry or SCV technique): their ratios should equal $n_{1} / n_{2}\left(n_{1}\right.$ and $n_{2}$ are the numbers of electrons involved in each electron transfer step). In the case of a mixture of two substances, the chance that the ratio of $n F A D^{1 / 2} \mathrm{C}$ terms equals exactly $0.5,1.0,1.5$ or 2.0 is extremely small due to differences in concentrations and in diffusion coefficients. Nevertheless, because the expert system does not use the value of the $n F A D^{1 / 2} C$ ratio as a criterion, a mixture of two compounds cannot be distinguished from a substance reducible in two subsequent steps.
Table 8 presents features evaluated by the expert system and the support for different hypotheses about the electrode reaction mechanism.

It can be seen, that the hypothesis about the absence of the net reaction is strongly supported. Inspection of the results for the type of transport to the electrode shows, that in the cases of the second electron transfer in the forward and in the backward branch, the support has gotten value either 1.0 or 0.0 : this results from the use of a restricted set of conditions if parallel reactions take place on the electrode (signals other than the first one). The conditions are then based exclusively on the number of peaks appearing in voltammograms differintegrated to various instances and because this is a Boolean feature, the final results for the transport type also acquire a Boolean character. These restrictions have a limited significance for the determination of the mechanism of the reaction, because conditions employing the type of the transport for signals other than the first one occur very seldom in the rules.

The semi-infinite linear diffusion has been found to be the most probable type of the transport for the first signals in the forward and in the

\section{TABLE 9}

Features with the strongest influence on the support pair for hypotheses about the reaction mechanism for the reduction of the mixture of $\mathrm{Cd}^{2+}$ and $\mathrm{Zn}^{2+}$ ions (F, B = Number of peaks in forward and backward branches of the SCV voltammogram)

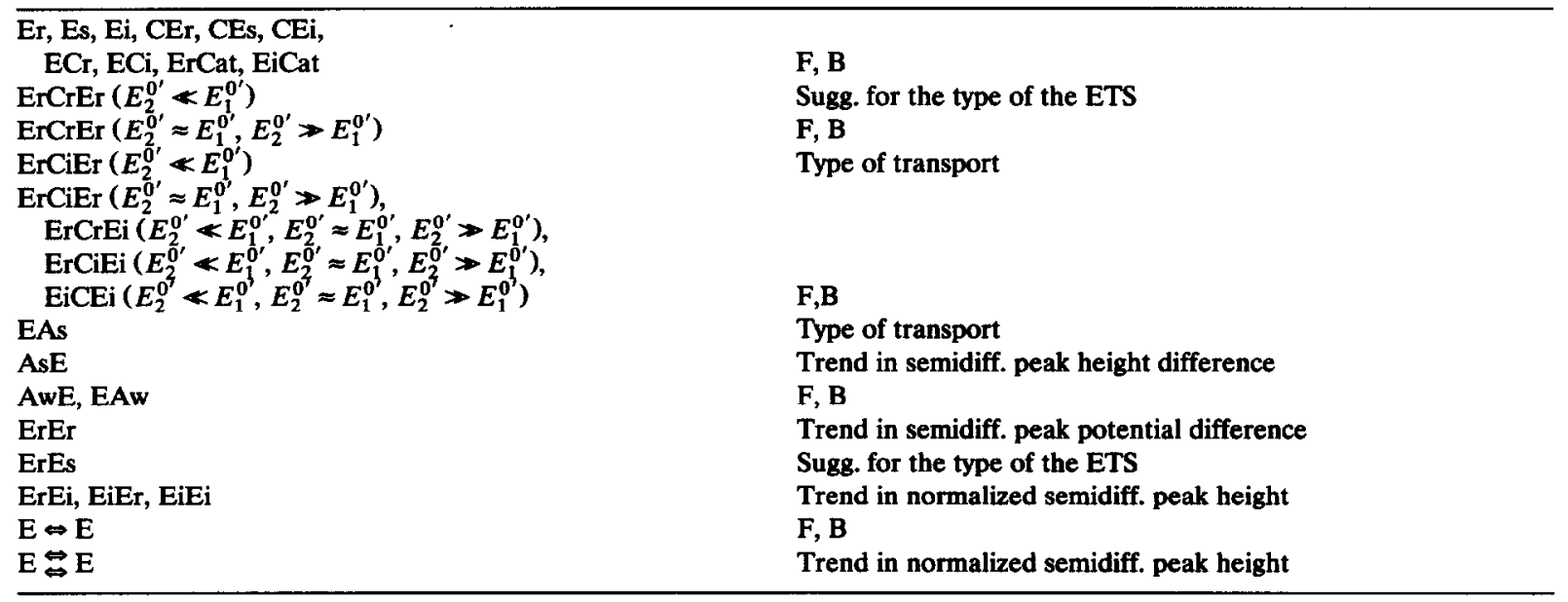


backward branch. For the second signals in both branches, the types of transport: LIM-LIN, LIN and LIN-KIN were equally possible. The first signal in the backward branch is suggested to be controlled by mixed linear and limited diffusion.

For the first and the second signal in each branch, $E$ and Es mechanisms are suggested, respectively. The only exception is the reoxidation of zinc, where the CEr mechanism has been found to be more probable. This can be explained by the accumulation effect (criteria for sugges- tions for ETS mechanisms assume semi-infinite linear diffusion) and possible complexation/ decomplexation phenomena.

In Table 9 the most influential features in the determination of the mechanism of the reaction are collected.

EAs mechanism, reduction of Methylene Blue in buffered water-ethanol solution

Methylene Blue is a compound well known to be reduced according to the EAs mechanism: the

TABLE 10

Support for features obtained during the elucidation of the mechanism of the electrode reaction of Methylene Blue in buffered water-ethanol solution (Acronyms: $\mathrm{F}=$ signal in the forward branch, $\mathrm{B}=$ signal in the backward branch)

\begin{tabular}{|c|c|c|c|}
\hline \multirow{2}{*}{$\begin{array}{l}F=2, B=2 \\
\text { Net reaction present }\end{array}$} & \multirow{2}{*}{$\frac{[1.000,1.000]}{[0.000,4.5 \mathrm{E}-4]}$} & \multirow{3}{*}{$\begin{array}{l}\text { Hidden and secondary signals: } \\
\text { Hidden signals } \\
\text { Secondary signals }\end{array}$} & \multirow{3}{*}{$\begin{array}{l}{[0.000,0.000]} \\
{[0.000,0.000]}\end{array}$} \\
\hline & & & \\
\hline & & & \\
\hline \multicolumn{2}{|c|}{ Suggestion for the type of the ETS } & B1: E & {$[0.216,0.462]$} \\
\hline F1: E & {$[0.241,0.604]$} & B1: Es & {$[0.179,0.75]$} \\
\hline F1: ECr & {$[0.008,0.442]$} & B1: CEr & {$[1.5 \mathrm{E}-16,0.667]$} \\
\hline F1: EiCat & {$[0.001,0.04]$} & B1: EiCat & {$[1.3 \mathrm{E}-16,0.333]$} \\
\hline F1: ErCat & [3.3EA, 0.039] & B1: ECi, CEi & {$[1.2 \mathrm{E}-16,0.667]$} \\
\hline F1: Es & {$[4.1 \mathrm{E}-5,0.936]$} & B1: ErCat & {$[7.4 \mathrm{E}-17,0.333]$} \\
\hline F1: other & {$[0.000,0.000]$} & B1: ECr & {$[0.0000 .000]$} \\
\hline F2: E & {$[0.177,0.440]$} & B2: E & {$[0.118,0.348]$} \\
\hline F2: Es & {$[0.063,0.699]$} & B2: Es & {$[0.106,0.750]$} \\
\hline F2: ECi, CEi & {$[0.000,0.667]$} & B2: EiCat & {$[4.6 \mathrm{E}-17,0.333]$} \\
\hline F2: CEr & {$[0.000,0.667]$} & B2: ECr & {$[4.6 \mathrm{E}-17,0.333]$} \\
\hline F2: ErCat & {$[0.000,0.333]$} & B2: $\mathrm{ECi}, \mathrm{CEi}$ & {$[4.6 \mathrm{E}-17,0.333]$} \\
\hline F2: EiCat & {$[0.000,0.333]$} & B2: ErCat & {$[0.000,0.333]$} \\
\hline F2: ECr & {$[0.000,0.000]$} & B2: CEr & {$[0.000,0.333]$} \\
\hline \multicolumn{4}{|l|}{ Transport to the electrode: } \\
\hline F1: LIM-LIN & {$[1.000,1.000]$} & B1: LIM-LIN & {$[0.929,0.929]$} \\
\hline F1: ADS & {$[1.000,1.000]$} & B1: ADS & {$[0.929,0.929]$} \\
\hline F1: LIN-KIN & {$[0.750,0.750]$} & B1: LIN & {$[0.071,0.071]$} \\
\hline F1: LIN & {$[2.5 \mathrm{E}-5,2.5 \mathrm{E}-5]$} & B1: other & {$[0.000,0.000]$} \\
\hline F1: KIN & {$[0.000,0.000]$} & & \\
\hline \multirow[t]{2}{*}{ F1: ADS-LIN } & {$[0.000,0.000]$} & B2: LIM-LIN & {$[1.000,1.000]$} \\
\hline & & B2: LIN & {$[1.000,1.000]$} \\
\hline F2: LIM-LIN & {$[1.000,1.000]$} & B2: LIN-KIN & {$[1.000,1.000]$} \\
\hline F2: LIN & {$[1.000,1.000]$} & B2: ADS & {$[1.000,1.000]$} \\
\hline F2: LIN-KIN & {$[1.000,1.000]$} & B2: KIN & {$[0.000,0.000]$} \\
\hline F2: ADS & {$[1.000,1.000]$} & B2: ADS-LIN & {$[0.000,0.000]$} \\
\hline F2: KIN & {$[0.000,0.000]$} & & \\
\hline F2: ADS-LIN & {$[0.000,0.000]$} & & \\
\hline \multicolumn{4}{|l|}{ System mechanism: } \\
\hline EAs & {$[0.413,0.413]$} & & \\
\hline ErEs & {$[2.6 \mathrm{E}-7,7.2 \mathrm{E}-6]$} & & \\
\hline $\mathrm{ErCrEr}, \mathrm{E} 2 \ll \mathrm{E} 1$ & {$[4.6 \mathrm{E}-8,2.5 \mathrm{E}-6]$} & & \\
\hline other & {$[0.000,0.000]$} & & \\
\hline
\end{tabular}


TABLE 11

Features with the strongest influence on the support pair for hypotheses about the reaction mechanism for the reduction of Methylene Blue (F, B = Number of peaks in forward and backward branches of the SCV voltammogram)

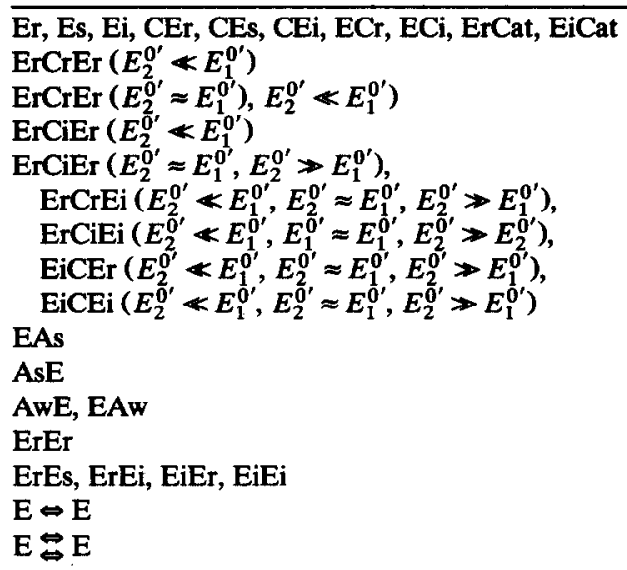

product of the electron transfer, the leuco form of the substance, is strongly adsorbed on the electrode surface $[25,27,28]$. The substrate, Methylene Blue itself, is also adsorbed but this effect is much weaker than the adsorption of the product, so it can be neglected.

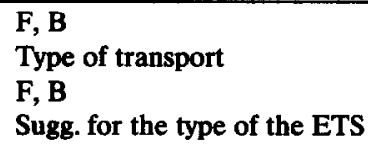

The results of the elucidation (determined features as well as the list of supports for different mechanisms) are presented in the Table 10.

Results for the type of transport generally allow to exclude certain types: for the signal for which in reality the transport is governed by

TABLE 12

Support for features obtained during the elucidation of the mechanism of reaction of $p$-nitrosophenol in buffered $\mathrm{KNO}_{3}$-ethanol solution (Acronyms: $F$ = signal in the forward branch, $B=$ signal in the backward branch)

\begin{tabular}{ll|lc}
\hline F $=1, \mathrm{~B}=2$ & {$[1.000,1.000]$} & Net reaction & {$[0.868,1.060]$} \\
\hline $\begin{array}{lll}\text { Hidden and secondary signals: } \\
\text { Hidden signals }\end{array}$ & {$[0.000,0.000]$} & \multicolumn{2}{l}{ Sugg. for the type of the ETS: } \\
Secondary signals & {$[1.0001 .000]$} & F1: E & {$[0.009,0.444]$} \\
& & F1: ECr & {$[1.5 E A, 0.34]$} \\
& & F1: EiCat & {$[1.5 E A, 0.322]$} \\
Type of the transport: & & F1: ECi, CEi & {$[1.5 E-4,0.321]$} \\
F1: LIN & {$[0.995,0.995]$} & F1: Es & {$[5.9 E-13,0.496]$} \\
F1: LIN-KIN & {$[0.750,0.750]$} & F1: ErCat & {$[1.2 \mathrm{E}-13,0.325]$} \\
F1: other & {$[0.000,0.000]$} & F1: CEr & {$[1.2 \mathrm{E}-13,0.321]$} \\
B1: LIM-LIN & {$[0.978,0.978]$} & B1: E & {$[0.258,0.548]$} \\
B1: LIN-KIN & {$[0.778,0.778]$} & B1: CEr & {$[0.011,1.000]$} \\
B1: LIN & {$[0.444,0.444]$} & B1: ErCat & {$[0.003,0.281]$} \\
B1: ADS & {$[0.111,0.111]$} & B1: EiCat & {$[0.003,0.281]$} \\
B1: ADS-LIN & {$[0.000,0.000]$} & B1: Es & {$[8.3 E-5,0.733]$} \\
B1: KIN & {$[0.000,0.000]$} & B1: ECi, CEi & {$[2.4 E-9,0.989]$} \\
& & B1: ECr & {$[0.000,0.000]$}
\end{tabular}

System mechanism:

$\mathrm{ErCiEr}, \mathrm{E} 2 \rightarrow \mathrm{E} 1$

$\mathrm{ErCrEr}, \mathrm{E} 2 \rightarrow \mathrm{E} 1$

other 
adsorption, this feature is ADS or LIM-LIN, while for signals associated with diffusional transport of the compound, the only conclusion is that two possibilities (KIN and ADS-LIN) are excluded.

Results for the mechanism of the electron transfer steps suggest, that all these reaction steps are fast and proceed without complications. From the data from Table 10 it can be found, that the result of the elucidation is mainly influenced by the analysis of the changes of heights of the voltammetric peaks with the variation of the scan rate.

The most influential features for the determination of the final support for the mechanisms are collected in Table 11.

\section{ErCiEr mechanism, reduction of p-nitro- sophenol}

$p$-Nitrosophenol has been used as a model compound for the experimental confirmation of the theoretical description of LSV curves for the ECE mechanism [3]. The mechanism of the reduction of this compound is known to include a relatively slow, irreversible chemical step between two fast electron transfers; the formal potential of the reduction of the intermediate is much more positive compared to the original substrate and therefore reduction signals totally overlap. The results of the expert system run are presented in the table below (Table 12).

During the investigations, two important features of the system have been found: the pres- ence of a net reaction and the appearance of a secondary signal in the third voltammetric halfcycle. The most supported type of transport for the forward peak is the linear diffusion and the LIN-KIN one. This suggests, that the influence of the chemical reaction on the flux of the electroactive substance is limited; indeed, the time-scale of the experiment is relatively short in comparison with the rate of the chemical reaction.

The support for the mechanism of the single electron transfer step in the forward branch is actually very low and on this basis no hypothesis can be considered as reasonably true. This is correct, because each signal does not belong to any of the listed classes.

The list of features that had the most important influence on the determination of the support is collected in Table 13.

\section{EiCEr mechanism, reduction of o-nitrophenol}

Nitrophenols have been extensively investigated and a number of papers devoted to the mechanism of their electrode reactions appeared [29-35]. The o-nitrophenol undergoes a complicated reaction, most probable consisting of the formation of a radical followed by its fast dismutation and protonation. The rate-determining step is the protonation [32], therefore the overall mechanism is EiCiEr (irreversible electron transfer, then an irreversible chemical step followed by a fast electron transfer step). The reported existence of a chemical step (protonation) prior to the first electron transfer, which is relatively fast,

\section{TABLE 13}

Features with the strongest influence on the support pair for hypotheses about the reaction mechanism for the reduction of p-nitrosophenol (F, B = number of peaks in forward and backward branches of the SCV voltammogram)

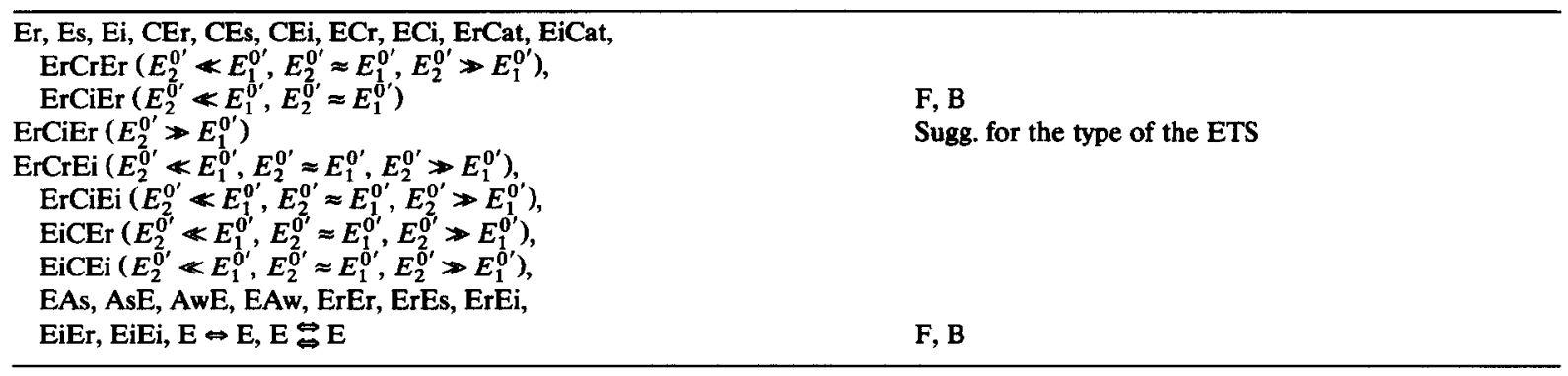


TABLE 14

Support for features obtained during the determination of the mechanism of $o$-nitrophenol reduction in mixed aqueous-ethanol solution (Acronyms: $F=$ signal in the forward branch, $B=$ signal in the backward branch)

\begin{tabular}{ll|ll}
\hline F $=1$, B $=1$ & {$[1.000,1.000]$} & Hidden signals & {$[0.000,0.060]$} \\
\cline { 1 - 2 } Net reaction & {$[1.000,1.000]$} & Secondary signals & {$[1.000,1.000]$} \\
\hline Type of the transport: & {$[0.859,0.859]$} & B1: LIN-KIN & {$[0.750,0.750]$} \\
F1: LIN & {$[0.333,0.333]$} & B1: LIN & {$[0.555,0.555]$} \\
F1: LIN-KIN & {$[0.000,0.000]$} & B1: LIM-LIN & {$[0.501,0.501]$} \\
F1: other & B1: other & {$[0.000,0.000]$} \\
\hline Sugg. for the type of the ETS: & & & \\
F1: Es & {$[0.577,0.821]$} & B1: CEr & {$[0.358,0.673]$} \\
F1: ECr & {$[0.319,0.412]$} & B1: ErCat & {$[0.171,0.322]$} \\
F1: EiCat & {$[0.185,0.239]$} & B1: EiCat & {$[0.171,0.322]$} \\
F1: ECi, CEi & {$[0.168,0.216]$} & B1: Es & {$[0.016,0.703]$} \\
F1: E & {$[2.8 E-5,0.361]$} & B1: E & {$[0.007,0.438]$} \\
F1: ErCat & {$[0.000,0.054]$} & B1: ECi, CEi & {$[0.000,0.315]$} \\
F1: CEr & {$[0.0000 .049]$} & B1: ECr & {$[0.000,0.000]$} \\
\hline
\end{tabular}

System mechanism

$\mathrm{EiCEr}, \mathrm{E} 2 \rightarrow \mathrm{E} 1 \quad[0.121,0.272]$

other $\quad[0.000,0.000]$

has no visible effect on the results in the time scale of experiments carried out by the expert system [34].
Results of the expert system run-are presented in Table 14.

The most characteristic features of this system

TABLE 15

Features with the strongest influence on the support pair for hypotheses about the reaction mechanism for the reduction of $o$-nitrophenol (F, B = Number of peaks in forward and backward branches of the SCV voltammogram)

\begin{tabular}{|c|c|}
\hline Er, Es & Hidden and secondary signals \\
\hline $\mathrm{Ei}$ & F, B \\
\hline CEr, CEs & Hidden and secondary signals \\
\hline $\mathrm{CEi}, \mathrm{ECr}, \mathrm{ECi}$ & F, B \\
\hline ErCat & Hidden and secondary signals \\
\hline EiCat, $\operatorname{ErCrEr}\left(E_{2}^{0^{\prime}} \ll E_{1}^{0^{\prime}}\right)$ & F, B \\
\hline $\operatorname{ErCrEr}\left(E_{2}^{0^{\prime}} \approx E_{1}^{0^{\prime}}\right)$ & Hidden and secondary signals \\
\hline $\operatorname{ErCrEr}\left(E_{2}^{0^{\prime}} \rightarrow E_{1}^{0^{\prime}}\right)$ & Net reaction \\
\hline $\operatorname{ErCiEr}\left(E_{2}^{0^{\prime}} \ll \mathrm{E}_{1}^{0^{\prime}}\right)$ & F, B \\
\hline $\operatorname{ErCiEr}\left(E_{2}^{0^{\prime}} \approx \mathrm{E}_{1}^{0^{\prime}}\right)$ & Hidden and secondary signals \\
\hline $\operatorname{ErCiEr}\left(E_{2}^{0^{\prime}}>E_{1}^{0^{\prime}}\right), \operatorname{ErCrEi}\left(E_{2}^{0^{\prime}} \ll E_{1}^{0^{\prime}}\right)$ & F, B \\
\hline $\operatorname{ErCrEi}\left(E_{2}^{0^{\prime}} \approx E_{1}^{0^{\prime}}, E_{2}^{0^{\prime}} \rightarrow E_{1}^{0^{\prime}}\right)$ & Hidden and secondary signals \\
\hline $\operatorname{ErCiEi}\left(E_{2}^{0^{\prime}} \ll E_{1}^{0^{\prime}}\right)$ & F, B \\
\hline $\operatorname{ErCiEi}\left(E_{2}^{0^{\prime}} \approx E_{1}^{0^{\prime}}, E_{2}^{0^{\prime}} \rightarrow E_{1}^{0^{\prime}}\right)$ & F, B \\
\hline $\operatorname{EiCEr}\left(E_{2}^{0^{\prime}} \ll E_{1}^{0^{\prime}}\right)$ & F, B \\
\hline $\operatorname{EiCEr}\left(E_{2}^{0^{\prime}} \approx E_{1}^{0^{\prime}}\right)$ & Hidden and secondary signals \\
\hline $\operatorname{EiCEr}\left(E_{2}^{0^{\prime}} \rightarrow E_{1}^{0^{\prime}}\right)$ & Type of transport \\
\hline $\operatorname{EiCEi}\left(E_{2}^{0^{\prime}} \ll E_{1}^{0^{\prime}}, E_{2}^{0^{\prime}} \approx E_{1}^{0^{\prime}}, E_{2}^{0^{\prime}} \rightarrow E_{1}^{0^{\prime}}\right)$ & F, B \\
\hline EAs, AsE & Secondary signals \\
\hline AwE, EAw & Hidden and secondary signals \\
\hline ErEr, ErEs, ErEi, EiEr, EiEi, E $\Leftrightarrow \mathrm{E}, \mathrm{E} \underset{\Leftrightarrow \mathrm{E}}{\Leftrightarrow}$ & F, B \\
\hline
\end{tabular}


are the appearance of the secondary signal (the signal in the third branch of the voltammogram) and the detection of the net reaction caused by the irreversibility of the chemical step. The type of the transport $m$ the case of the first reduction signal has been found to be linear diffusion (LIN, most probably) and mixed kinetic effect and linear diffusion (LIN-KIN, less probably). The order of these features on the ranking list should be, actually, reverse; this discrepancy can be explained by a probably relatively small contribution of the chemical reaction the transport of the electroactive compound to the electrode.

Table 15 presents the most influence features for the support for each hypothesis about the mechanism of the reaction.

\section{DISCUSSION}

For all compounds, the expert system assigned the highest support to the correct mechanism of the electrode reaction. There is also a very clear difference in support between the first and next hypotheses on the list of electrode reactions, which facilitates the easy distinction between alternative hypotheses.

The values of numbers composing the supporting pairs should not be considered as probabilities: support is quite closely related to the probability, but the use of relative calculations in some of the statistical tests and the intermixing of Boolean and fuzzy facts makes this relation not straightforward. In these terms, support $[0.1,0.1]$ does not mean, that the probability that the considered mechanism is false is $90 \%$ : instead, the support should be compared to supports obtained for other mechanisms. From experience, supports above approx. 0.01 can be interpreted as acceptation of the hypothesis and below this limit, as rejection.

The time necessary for a complete elucidation is quite short: the fill cycle of work, including all experiments, takes approx. 4-6 h. It could be slightly shortened if a more powerful computer is used, however, most of the time is spent on experiments. All experimental results are available in such a form, that they can be processed by other application programs. The report facility delivers the full list of suggested mechanisms and features determined during the ES run in a form similar to the tables presented in the preceding sections of this chapter.

The inspection of partial results leads to the conclusion, that Boolean features like the number of visible electron transfer steps, the presence of hidden peaks etc. are determined properly; the same applies to the detection of a net chemical reaction in the system. Results are less informative for suggestions for the type of electron transfer step and in the determination of the type of transport of the electroactive substance for separate signals.

Problems with the first of these features stem from the fact, that the group of mechanisms of single electron transfer steps for which rules are implemented is quite limited; additionally, rules have been designed under the assumption, that the transport of electroactive substance proceeds according to the semi-infinite linear diffusion scheme. It is important to notice, that rules for some mechanisms are more strict (e.g., $\mathrm{d} E_{\mathrm{p}} /$ $\mathrm{d} \ln v=0$ for $\mathrm{Er}$ ), while for others they are more general $\left(\mathrm{d} E_{\mathrm{p}} / \mathrm{d} \ln v\right.$ not constant for ErCat): one can expect that the support obtained in the first case will be less than the support for the second case.

The result for the type of transport to the electrode suffers from the lack of corrections for the effect of parallel reactions proceeding on the electrode. As a consequence, all available tests are only applied to the investigation of the first reduction and oxidation signals. For other signals, only a reduced set of criteria is used, increasing the chance for misinterpretation of the experimental data. In possible future extensions of the expert system, particular attention should be paid to the improvement of this part of the set of rules. Partial improvement of the results could be obtained by the application of statistical tests more sophisticated than those currently used to investigate the trend and the values of the data.

The fact, that the right mechanism is obtained even in situations, where the relative support for one or two simple features does not reflect the truth means that there is a redundancy in the 
structure of rules. This redundancy decreases the chance for making mistakes in the determination of the support for hypotheses about the mechanism and thanks to it the final results are more reliable.

The operation of the expert system requires only a small number of interactions with the operator. Almost all information necessary for the expert system is provided at the beginning of the ES run and thereafter the system can work independently until the result is obtained.

\section{REFERENCES}

1 M. Pałys, M. Bos and W.E. Van der Linden, Anal. Chim. Acta, 231 (1990) 59.

2 M. Pałys, M. Bos and W.E. Van der Linden, Anal. Chim. Acta, 248 (1991) 429.

3 R.S. Nicholson and I. Shain, Anal. Chem., 37 (1965) 178.

4 A.M. Bond, Modern Polarographic Methods in Analytical Chemistry, Dekker, New York, 1980.

5 R. Guidelli, in A.J. Bard (Ed.), Chemical Reactions in Polarography, Electroanalytical Chemistry, Vol. 5, Dekker, New York, 1971, p. 149.

6 K.B. Oldham, Anal. Chem., 58 (1986) 2296.

7 J.C. Myland, K.B. Oldham and C.G. Zoski, J. Electroanal. Chem., 193 (1985) 3.

8 S.O. Engblom and K.B. Oldham, Anal. Chem., 62 (1990) 625.

9 I.D. Dobson, N. Taylor and L.R.H. Tipping, in M.R. Smyth, J.G. Vos (Eds.), Electrochemistry, Sensors and Analysis, Elsevier, Amsterdam, 1986, p. 61.

10 R.S. Nicholson and I. Shain, Anal. Chem., 36 (1964) 706.

11 M. Goto and D. Ishii, J. Electroanal. Chem., 61 (1975) 361.

12 P. Dalrymple-Alford, M. Goto and K.B. Oldham, J. Electroanal. Chem., 85 (1977) 1.
13 F.C. Anson, Anal. Chem., 38 (1966) 54.

14 M.H. Hulbert and I. Shain, Anal. Chem., 42 (1970) 162.

15 S.W. Feldberg, in J.S. Matson, H.B. Mark and H.C. MacDonald (Eds.), Electrochemistry. Calculation Simulation, Instrumentation, Vol. 2, Dekker, New York, 1972, p. 185.

16 M.G. Grenness and K.B. Oldham, Anal. Chem., 44 (1972) 1121.

17 M. Goto and K.B. Oldham, Anal. Chem., 45 (1973) 2043.

18 M. Goto and K.B. Oldham, Anal. Chem., 48 (1976) 1671.

19 J.C. Imbeaux and J.M. Saveant, J. Electroanal. Chem., 44 (1973) 169.

20 F. Ammar and J.M. Saveant, J. Electroanal. Chem., 47 (1973) 215.

21 J.M. Saveant and D. Tessier, J. Electroanal. Chem., 61 (1975) 251.

22 C.P. Andrieux, J.M. Saveant and D. Tessier, J. Electroanal. Chem., 63 (1975) 429.

23 J.M. Saveant and D. Tessier, J. Electroanal. Chem., 65 (1975) 57.

24 R. Bowling and R.L. McCreery, Anal. Chem., 60 (1988) 605.

25 R.H. Wopschall and I. Shain, Anal. Chem., 39 (1967) 1514.

26 J.W. Ashley jr., and Reilley, J. Electroanal. Chem., 7 (1964) 253.

27 R. Brdicka, Coll. Czech. Chem. Commun., 12 (1947) 522.

28 W. Kemula, Z. Kublik and A. Axt, Roczniki Chem., 35 (1961) 1009.

29 A.C. Testa and W.H. Reinmuth, J. Am. Chem. Soc., 83 (1961) 784.

30 C. Corvaja, G. Farnia and E. Vianello, Electrochim. Acta, 11 (1966) 919.

31 G. Farnia, G. Mengoli and E. Vianello, J. Electroanal. Chem., 50 (1974) 73.

32 G. Farnia, A. Roque da Silva and E. Vianello, J. Electroanal. Chem., 57 (1974) 191.

33 L. Camacho, A. Heras, J.L. Avila and F. Garcia Blanco, J. Electroanal. Chem., 172 (1984) 161.

34 A.M. Heras, E. Munoz, J.L. Avila and L. Camacho, Electrochim. Acta, 32 (1987) 1495.

35 A.M. Heras, E. Munoz, J.L. Avila, L. Camacho and J.L. Cruz, J. Electroanal. Chem., 243 (1988) 293. 